\title{
Presencia del virus de Epstein-Barr en casos colombianos de linfoma de Hodgkin y su relación con la respuesta al tratamiento
}

\begin{abstract}
Sandra Quijano¹, Carlos Saavedra², Susana Fiorentino³, Oscar Orozco*, María Mercedes Bravo ${ }^{1}$

1 Laboratorio de Inmunología, Instituto Nacional de Cancerología, Bogotá, D.C., Colombia.
2 Grupo de Patología, Instituto Nacional de Cancerología, Bogotá, D.C., Colombia.
${ }^{3}$ Grupo de Inmunobiología, Pontificia Universidad Javeriana, Bogotá, D.C., Colombia.
* In memoriam

En el desarrollo y patogénesis del linfoma de Hodgkin se ha propuesto al virus de Epstein-Barr como posible factor etiológico debido a la detección de ADN viral en las células de ReedSternberg en un subgrupo de tumores y a los altos niveles de expresión de la proteína latente de membrana 1 (LMP-1). El objetivo de este estudio fue determinar la presencia de virus de Epstein-Barr en 67 ganglios linfáticos de pacientes con diagnóstico confirmado de linfoma de Hodgkin mediante hibridación in situ para la detección de transcritos de ARN del virus de Epstein-Barr e inmunohistoquímica para la detección de la proteína oncogénica LMP-1. La presencia del virus se relacionó con el subtipo histológico, la respuesta al tratamiento de los pacientes y el fenotipo del infiltrado linfocitario. En el $67 \%$ de los casos se detectaron transcritos de virus de Epstein-Barr, la proteína LMP-1 se detectó en $56,7 \%$ de los casos en la célula tumoral de Reed-Sternberg. La presencia del virus en cada tipo histológico fue de $69,81 \%$ en esclerosis nodular, $85,71 \%$ en celularidad mixta y $40 \%$ en clásico. El virus de Epstein-Barr se detectó con mayor frecuencia en niños (84,2\%) en comparación con los adultos $(60,4 \%)$ y los pacientes positivos para el virus mostraron mejor respuesta al tratamiento, reflejada en una menor tendencia a presentar recaídas. El análisis del infiltrado mostró un predominio de linfocitos T CD4 y presencia de linfocitos T CD8, con mayor expresión de ambas subpoblaciones en casos positivos para virus de Epstein-Barr. Los resultados muestran un alto porcentaje de infección por virus de Epstein-Barr con una probable implicación significativa en la respuesta al tratamiento, lo que sugiere que la detección de virus de Epstein-Barr se podría usar como marcador de pronóstico en este tipo de linfoma.
\end{abstract}

Palabras clave: linfoma de Hodgkin, virus de Epstein-Barr, Colombia.

Epstein-Barr virus presence in Colombian Hodgkin Iymphoma cases and its relation to treatment response

The role of Epstein-Barr virus as etiologic agent in Hodgkin lymphoma $(\mathrm{HL})$ development has been supported by the detection of viral DNA in the Reed-Sternberg cell in a subset of HL, and the high levels of latent membrane protein 1 expression in these tumors. To gain further evidence of this relationship, lymph nodes from 67 patients with $\mathrm{HL}$ were analyzed for the presence of Epstein-Barr virus using EBERs in situ hybridization and LMP-1 immunohistochemistry. Virus presence was related to histological subtype, patients' treatment response and tumor infiltrating lymphocytes phenotype. EBERs transcripts were found in $67 \%$ of the cases and LMP-1 in the Reed-Sternberg tumor cells at a $56.7 \%$ rate. The prevalence, as determined by histological subtype, was $69.81 \%$ for nodular sclerosing, $85.71 \%$ for mixed cellularity and $40 \%$ for lymphocyte-rich. Epstein-Barr virus presence was more frequent in children (84.2\%) in comparison with adults $(60.4 \%)$. Positive patients presented higher failure-free survival rates than Epstein-Barr virus negative patients. CD4 positive infiltrating T cells were present in a higher proportion in relation to CD8 positive $T$ infiltrating cells, the mean percentages for both subsets were higher in Epstein-Barr virus positive cases. A high percentage of Epstein-Barr 
virus was present in $\mathrm{HL}$ with a probable association with treatment response. This suggests an application of Epstein-Barr virus detection to use as a prognosis marker in treatment response for HL cases.

Key words: Hodgkin's lymphoma, Epstein Barr virus, Colombia.

El 24,3\% de los linfomas diagnosticados y tratados en el Instituto Nacional de Cancerología (INC) en Bogotá, Colombia, corresponde a linfoma de Hodgkin (1). El linfoma de Hodgkin se caracteriza por la presencia de las células neoplásicas de Reed-Sternberg y sus variantes, acompañadas de una gran población reactiva de células infiltrantes que constituyen más del $98 \%$ de la masa tumoral (2). El virus de Epstein-Barr se ha considerado como posible factor etiológico en el desarrollo de esta neoplasia debido a que se detecta tanto ADN como ARN virales en las células tumorales de Reed-Sternberg en el $40 \%$ al $100 \%$ de los casos (3-6). Se ha sugerido que este virus podría estar implicado en los mecanismos de transformación celular (6-8). El papel del virus de Epstein-Barr en transformación maligna es soportado por el hecho que la proteína latente de membrana tipo 1 (LMP1), codificada en el genoma viral, es expresada en las células de Reed-Stenberg y su expresión resulta en activación del factor de transcripción NFkB, expresión de la proteína anti-apoptótica Bcl2 , de marcadores de activación y moléculas de adhesión y secreción de citocinas, eventos que en conjunto promueven la persistencia del virus de Epstein-Barr mediante la evasión de la apoptosis y de la respuesta de linfocitos $T$ citotóxicos por parte de la célula tumoral infectada (7-9).

La frecuencia de casos de linfoma de Hodgkin con células de Reed-Stenberg positivas para virus de Epstein-Barr muestra una considerable variabilidad geográfica: $47 \%$ en casos norteamericanos $(5,9), 50 \%$ y $45 \%$ en casos europeos (5,9 ), 54\% en Argentina (10), 70\% en México (11), 60\% en Corea (12), 72\% en Argelia

\footnotetext{
Correspondencia:

María Mercedes Bravo, Laboratorio de Inmunología, Instituto Nacional de Cancerología, Calle $1 \mathrm{~N}^{\circ}$ 9-85, Bogotá, D.C., Colombia

Teléfono: (571) 334 0959; fax: (571) 3341360

e-mail: mbravo@ incancerologia.gov.co

Recibido: 15/08/03; aceptado: 31/05/04
}

(13), $96 \%$ en Perú (14), $40 \%$ en Costa Rica (15), $64,1 \%$ de casos en adultos en Brasil (16) y $100 \%$ en casos pediátricos de Honduras (17). Basados en la alta prevalencia de virus de Epstein-Barr en el linfoma de Hodgkin, algunos autores han sugerido que el linfoma de Hodgkin se puede subclasificar como virus de Epstein-Barr positivo o negativo dependiendo del subtipo histológico, de la edad en el momento del diagnóstico, del sexo y de la localización geográfica (18). Sin embargo, los estudios con relación a la importancia de la presencia del virus de EpsteinBarr y el pronóstico en el linfoma de Hodgkin han sido controversiales ya que en algunos reportes se describe al virus de Epstein-Barr como un factor pronóstico positivo $(19,20)$, mientras que en otros no se encuentra asociación con una mejor respuesta de los pacientes al tratamiento (21).

El objetivo de este estudio fue detectar la presencia de virus de Epstein-Barr en casos colombianos de linfoma de Hodgkin y relacionarla con los diferentes subtipos histológicos, los estadios clínicos tumorales, la respuesta al tratamiento de los pacientes y las características inmunofenotípicas del infiltrado linfocitario.

\section{Materiales y métodos}

\section{Pacientes}

Se incluyeron 67 pacientes con diagnóstico de linfoma de Hodgkin que asistieron a consulta al Instituto Nacional de Cancerología en Bogotá entre agosto de 1994 y diciembre de 1998, a quienes se les tomó una biopsia de ganglio linfático antes de iniciar el tratamiento. Los datos clínicopatológicos y de seguimiento de los pacientes se obtuvieron de sus historias clínicas. Los pacientes adultos menores de 65 años recibieron seis ciclos de quimioterapia con ABVD (doxorrubicina, bleomicina, vinblastina, dacarbazina) y radioterapia de consolidación si el volumen tumoral inicial era mayor de $8 \mathrm{~cm}$. Los pacientes mayores de 65 años en estadios I y II se trataron con radioterapia solamente, y los estadios III y 
IV recibieron seis ciclos de ChIVPP (clorambucil, vinblastina, procarbazina, prednisona). Los pacientes menores de 16 años en estadios I y II recibieron cuatro ciclos de OPPA (vincristina, prednisona, procarbazina, doxorrubicina) o dos ciclos de OPPA y dos ciclos de COPP (ciclofosfamida, vincristina, prednisona, procarbazina), todos con radioterapia sobre los campos comprometidos; en menores de seis años: dos ciclos de OPPA y dos de COPP, sin radioterapia. En estadios III y IV, recibieron tres ciclos de OPPA y tres ciclos de COPP, con radioterapia sobre los campos comprometidos excepto en los menores de 6 años.

\section{Especímenes clínicos}

El origen anatómico de las 67 biopsias fue el siguiente: 46 cervicales, 7 supraclaviculares, 6 inguinales, 5 axilares y 3 retroperitoneales. Todos los casos se clasificaron histológicamente de acuerdo con los criterios propuestos por la Organización Mundial de la Salud (OMS) (22). Se conservó material en congelación y en parafina. Las biopsias congeladas se usaron para la inmunotipificación y el análisis del infiltrado reactivo, y las biopsias incluidas en parafina se usaron para la detección de transcritos nucleares del virus de Epstein-Barr por medio de hibridación in situ y para el análisis de la expresión de LMP1 por inmunoperoxidasa.

\section{Anticuerpos}

Se utilizaron los siguientes anticuerpos monoclonales para inmunofenotipo: CD2 (Dako M720), CD3 (Dako M756), CD4 (Dako M716), CD8 (Dako M707), CD20 (Dako M0755), CD30 (Dako M0723) y CD45 (Dako M0701). Para la detección de virus de Epstein-Barr se utilizó el anticuerpo monoclonal anti-LMP-1 (Dako M0897).

\section{Técnica de desenmascaramiento de antígeno}

El análisis de la expresión de LMP-1 del virus de Epstein-Barr, CD30 y CD45 $(23,24)$, se realizó sobre cortes en parafina utilizando la solución de desenmascaramiento de antígeno (Dako S3308), que contiene tampón citrato-fosfato $0,01 \mathrm{~mol} / \mathrm{L}$, $\mathrm{pH}$ 6,0; previamente, los tejidos se desparafinaron 30 minutos a $100^{\circ} \mathrm{C}$ y se hidrataron; posteriormente, se sumergieron en la solución precalentada a $95^{\circ} \mathrm{C}$ durante 40 minutos. Luego, se procedió con la técnica de inmunoperoxidasa.

\section{Técnica inmunohistoquímica (inmunoperoxidasa)}

Se empleó la técnica de inmunoperoxidasa $A B C$, utilizando el estuche Vectastain ABC (Vector PK4000). La actividad de peroxidasa endógena se bloqueó con una solución de metanol- $\mathrm{H}_{2} \mathrm{O}_{2}$ al 0,3\% durante 30 minutos; después se incubó con suero normal de caballo (suero de bloqueo) durante 20 minutos a temperatura ambiente. Posteriormente, se adicionaron los anticuerpos primarios durante 1 hora a temperatura ambiente; luego, se incubó con el anticuerpo secundario (anti-lgG de ratón marcado con biotina) durante 40 minutos y se realizó una última incubación con estreptavidinabiotina-peroxidasa durante 1 hora. Para el revelado se utilizaron diaminobencidina $(1 \mathrm{mg} / \mathrm{ml})$ y $\mathrm{H}_{2} \mathrm{O}_{2}$; la contratinción de los tejidos se hizo con hematoxilina de Mayer. Como control negativo en cada caso se omitió el anticuerpo primario y en su lugar se colocó PBS.

\section{Hibridación in situ}

La hibridación in situ se realizó sobre cortes de parafina; se utilizó el estuche de hibridación in situ (Dako K5201) y la sonda complementaria a los transcritos ARN de EBER-1 y EBER-2 de virus de Epstein-Barr marcada con fluoresceína (Dako Y5200). Como control positivo se utilizó la línea celular B95.8 (línea de linfocitos B de mono ardilla infectados con virus de Epstein-Barr) (25). Como control negativo se empleó la línea celular Ramos (línea celular linfoblastoide negativa para virus de Epstein-Barr) (25). Previamente, los tejidos se desparafinaron, hidrataron y se sometieron a un pretratamiento con proteinasa $\mathrm{K}$ por 30 minutos a temperatura ambiente. La sonda anti-EBER marcada con fluoresceína se incubó durante 1 hora y media a $55^{\circ} \mathrm{C}$ en cámara húmeda y, posteriormente, se adicionó el conjugado antifluoresceína marcado con fosfatasa alcalina durante 30 minutos. El revelado se hizo con una solución de NBT y BCIP durante 60 minutos y la contratinción con eosina por 10 segundos.

\section{Análisis estadístico}

Se empleó el paquete estadístico SPSS, versión 11.5 , y se aplicaron las pruebas de $\chi^{2}$ y la prueba 
exacta de Fisher. Se consideró como diferencia significativa una $p<0,05$. La supervivencia libre de recurrencia y la supervivencia global se definieron como el tiempo transcurrido desde el inicio del tratamiento hasta la aparición de enfermedad recurrente o la muerte. Las curvas de supervivencia total y supervivencia libre de recurrencia se calcularon de acuerdo con el método de Kaplan-Meier y las diferencias entre grupos se evaluaron con la prueba de log-rank, para el análisis multivariado se empleó el modelo de regresión de Cox.

\section{Resultados}

\section{Hallazgos clínicos e histopatológicos}

El $71,6 \%$ de los pacientes eran adultos (48/67) con un rango de edad entre 16 y 83 años; $58,2 \%$ eran adultos jóvenes con edades entre 16 y 49 años y $13,4 \%$ eran adultos viejos mayores de 50 años. El $28,4 \%$ eran niños (19/67) con un rango de edad entre los 3 y los 15 años. Los casos se clasificaron en los siguientes estadios clínicos: 16 casos en estadio I ( $23,88 \%), 18$ en estadio II (26,87\%), 22 en estadio III (32,84\%), 9 casos en estadio IV $(13,43 \%)$ y 2 casos no determinados $(2,99 \%)$.

Dentro del tipo clásico de linfoma de Hodgkin, el tipo histológico más frecuente fue el de esclerosis nodular, $79,1 \%$ (53 casos), seguido del tipo de celularidad mixta, $10,45 \%$ (7 casos), rico en linfocitos, $7,46 \%$ (5 casos) y 2,99\% (2 casos) de predominio linfocítico. El subtipo de esclerosis nodular predominó en todos los grupos de edad; el grupo que mostró mayor número de casos de celularidad mixta fue el de mayores de 50 años.

De los 67 pacientes iniciales, 10 abandonaron el tratamiento o lo finalizaron en otra institución. Durante el período de seguimiento (media: 23,8 meses), 13 pacientes presentaron recurrencias y cuatro fallecieron.

\section{Presencia de virus de Epstein-Barr en casos de linfoma de Hodgkin}

En el cuadro 1 se presentan los resultados de la detección del virus de Epstein-Barr, tanto a nivel de transcritos EBER como de proteína LMP-1 (figura $1 \mathrm{~A}$ ). En el $67 \%$ de los casos (45/67) se observaron, con intensidad acentuada, los transcritos nucleares EBER-1 y EBER-2 en el núcleo de la célula tumoral de Reed-Stenberg (figura 1, B). Se observó una alta prevalencia de virus de Epstein-Barr en todos los grupos de edad; los mayores porcentajes se presentaron en niños y en adultos viejos. Igualmente, se observó alto porcentaje de infección en todos los subtipos histológicos, con las mayores prevalencias en los subtipos de celularidad mixta y esclerosis nodular.

La LMP-1 se detectó en la célula tumoral de ReedStenberg con un patrón difuso y granular en el citoplasma y paranuclear (zona de Golgi) (figura 1C). El porcentaje de positividad fue del 56,7\% (38/67 casos) y se observó un mayor porcentaje de expresión en niños en comparación con adultos $(p=0,03)$. Al analizar el porcentaje de expresión de LMP-1, según el tipo histológico, se encontró expresión de LMP-1 en linfoma de Hodgkin clásico (esclerosis nodular, celularidad mixta y rico en linfocitos), ningún caso del subtipo histológico de predominio linfocítico fue positivo.

No se encontraron diferencias significativas entre la presencia o ausencia de virus de Epstein-Barr y las características clínico-patológicas (sexo, edad, estadio clínico tumoral, grado de esclerosis nodular).

\section{Respuesta al tratamiento}

En el grupo de pacientes estudiado la supervivencia global a 60 meses fue del $93 \%$ y la supervivencia libre de recurrencias del $77,2 \%$.

El análisis univariado de los parámetros clínicopatológicos y el estado viral en relación con la supervivencia mostró una asociación significativa entre la detección de virus de Epstein-Barr en el tumor y la supervivencia libre de enfermedad. A 60 meses encontramos una asociación significativa entre la presencia de virus de EpsteinBarr y la supervivencia libre de enfermedad, la supervivencia libre de enfermedad fue del $93,55 \%$ para los pacientes positivos para EBER y del $91,8 \%$ para los pacientes positivos para LMP-1, mientras que para pacientes negativos para EBER fue del $56 \%$ y para los negativos para LMP1 del $50 \%$ [p(LR-test) 0,0008 y 0,0002, respectivamente] (cuadro 2, figura 2). No se encontraron diferencias significativas en la supervivencia libre de enfermedad con relación a 
Cuadro 1. Prevalencia de infección por virus de Epstein-Barr (hibridación in situ para EBER e inmunoperoxidasa para LMP-1).

\begin{tabular}{|c|c|c|c|c|c|c|c|c|}
\hline & \multicolumn{4}{|c|}{ EBER } & \multicolumn{4}{|c|}{ LMP-1 } \\
\hline & \multicolumn{2}{|c|}{ Positivos } & \multicolumn{2}{|c|}{ Negativos } & \multicolumn{2}{|c|}{ Positivos } & \multicolumn{2}{|c|}{ Negativos } \\
\hline & $\mathbf{n}$ & $\%$ & $\mathrm{n}$ & $\%$ & $\mathbf{n}$ & $\%$ & n & $\%$ \\
\hline $\begin{array}{l}\text { Número de casos } \\
\text { Grupos de edad (años) }\end{array}$ & 45 & 67 & 22 & 33 & 38 & 56,7 & 29 & $\begin{array}{l}43,3 \\
0-15^{*}\end{array}$ \\
\hline 16 & 84,2 & 3 & 15,8 & 14 & 73,7 & 5 & 26,3 & \\
\hline $16-49$ & 20 & 51,3 & 19 & 48,7 & 17 & 43,6 & 22 & 56,4 \\
\hline$>50$ & 9 & 100 & & & 7 & 77,8 & 2 & 22,2 \\
\hline \multicolumn{9}{|l|}{ Sexo } \\
\hline Hombres & 35 & 72,9 & 13 & 27,1 & 29 & 60,4 & 19 & 39,6 \\
\hline Mujeres & 10 & 52,6 & 9 & 47,3 & 9 & 47,4 & 10 & 52,6 \\
\hline \multicolumn{9}{|l|}{ Estadios clínicos } \\
\hline I & 10 & 62,5 & 6 & 37,5 & 10 & 62,5 & 6 & 37,5 \\
\hline I & 12 & 66,6 & 6 & 33,4 & 12 & 66,6 & 6 & 33,4 \\
\hline II & 16 & 72,7 & 6 & 27,3 & 16 & 72,7 & 6 & 27,3 \\
\hline $\mathrm{V}$ & 5 & 55,5 & 4 & 44,5 & 5 & 55,5 & 4 & 44,5 \\
\hline ND & 2 & 100 & 0 & 0 & 2 & 100 & 0 & 0 \\
\hline \multicolumn{9}{|l|}{ Tipo histológico } \\
\hline Esclerosis nodular & 37 & 69,8 & 16 & 30,2 & 31 & 58,5 & 22 & 41,5 \\
\hline Celularidad mixta & 6 & 85,7 & 1 & 14,3 & 5 & 71,4 & 2 & 28,6 \\
\hline Rico en linfocitos & 2 & 40 & 3 & 60 & 2 & 40 & 3 & 60 \\
\hline Predominio linfocítico & 0 & 0 & 2 & 100 & 0 & 0 & 2 & 100 \\
\hline \multicolumn{9}{|l|}{ Grado de esclerosis } \\
\hline I & 25 & 69,4 & 11 & 30,6 & 25 & 69,4 & 11 & 0,6 \\
\hline II & 12 & 70,6 & 5 & 29,4 & 12 & 70,6 & 5 & 29,4 \\
\hline
\end{tabular}

* $p<0,05$

edad, estado clínico o tipo de tratamiento. En relación con la supervivencia global no se encontraron asociaciones significativas (cuadro 2).

En el análisis multivariado, la presencia de virus de Epstein-Barr fue un parámetro de pronóstico de supervivencia libre de enfermedad, independiente de edad, estado clínico y tipo de tratamiento. Considerando un riesgo relativo (RR) de recurrencia de 1 para pacientes positivos para EBER, el RR de recurrencia para los pacientes negativos para EBER fue de 8,06 (IC95\%, 1,8233,86 ), $p=0,006$ (cuadro 3).

\section{Hallazgos inmunohistoquímicos}

En el 94\% (63/67) de los casos se observó expresión de CD30 en la célula tumoral de ReedStenberg (figura 1D). EI CD45 fue positivo en todos los casos, en el infiltrado no neoplásico.

En el $100 \%$ de los casos se observó presencia de linfocitos T CD2 y CD3 positivos en el infiltrado, con predominio de linfocitos T CD4 en el 50,7\%
(34/67) de los casos, de linfocitos T CD8 en el $23,9 \%$ (16/67) de ellos; $25,4 \%$ (17/67) de los casos presentó porcentajes similares de detección de CD4 y CD8. En todos los tipos histológicos se observó predominio de linfocitos T CD4, el porcentaje de expresión fue $80 \%$ en casos de celularidad mixta, $66,7 \%$ en esclerosis nodular, $100 \%$ en ricos en linfocitos y $60 \%$ en predominio linfocítico.

Con respecto a la infección por virus de EpsteinBarr, se detectaron mayores porcentajes de linfocitos T CD4 y CD8 en casos positivos para EBER $(68,8 \%$ y $65,1 \%)$ que en casos negativos $(31,2 \%$ y $34,9 \%)$. Para casos LMP-1 positivos y negativos se observaron diferencias similares. Estas diferencias no fueron significativas.

\section{Discusión}

En contraste con la mayoría de malignidades, la curva de incidencia para edad en linfoma Hodgkin es bimodal. En países desarrollados se observa un pico de incidencia entre los 15 y los 34 años y 


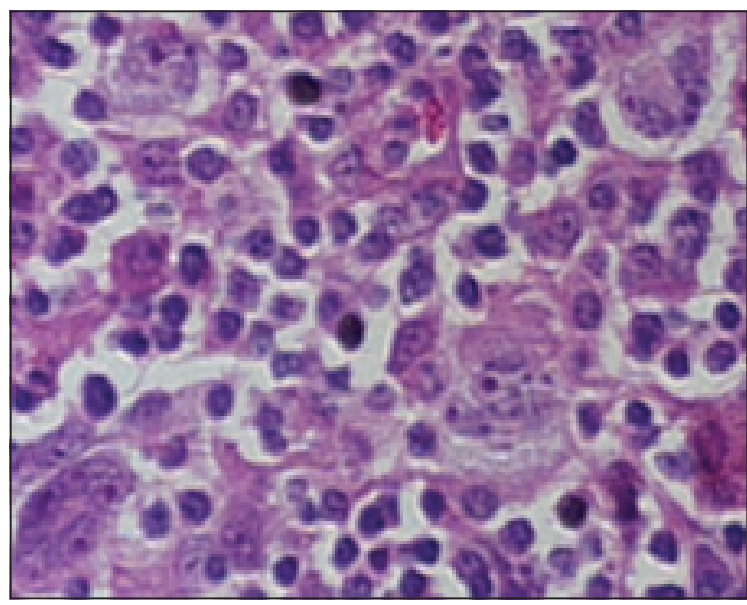

A

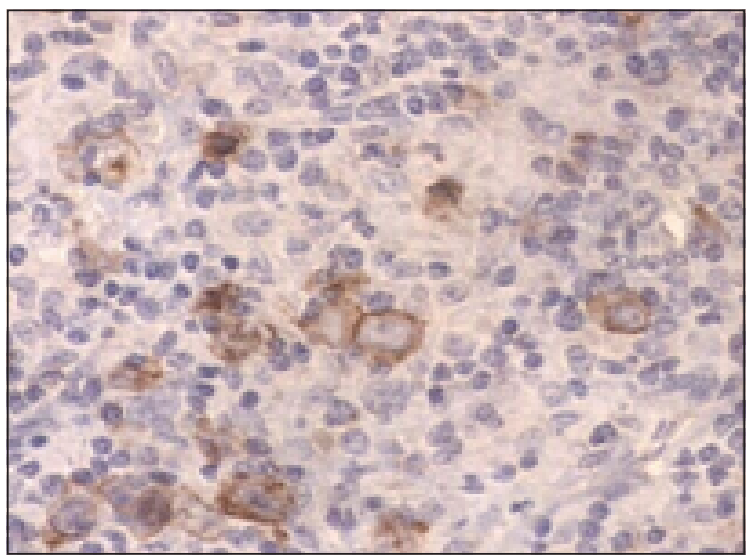

C

Figura 1. Caso de esclerosis nodular en el que se observan células tumorales. Tinción Hematoxilina-Eosina (A), presencia de transcritos virales EBER (B), detección de LMP-1 (C), y de CD30 (D) en las células tumorales.

declina en la cuarta década. En países en desarrollo se observa una alta incidencia en niños (26).

Se han descrito cuatro patrones epidemiológicos de la enfermedad:

1) Países en desarrollo: predominio de los subtipos histológicos de celularidad mixta y depleción linfocitaria, con alta incidencia en niños y un segundo pico de incidencia en adultos viejos.

2) Países desarrollados, particularmente en regiones urbanas: predominio del subtipo histológico de esclerosis nodular, con alta incidencia en adultos jóvenes y baja incidencia en niños.

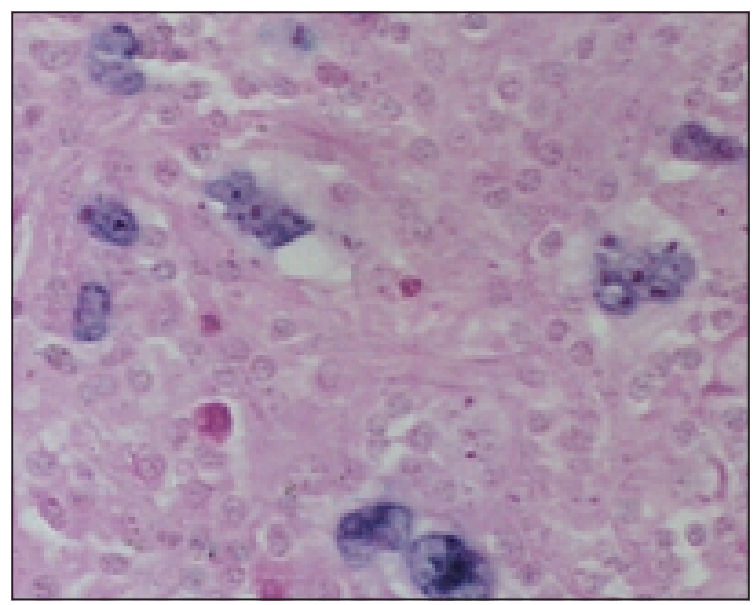

B

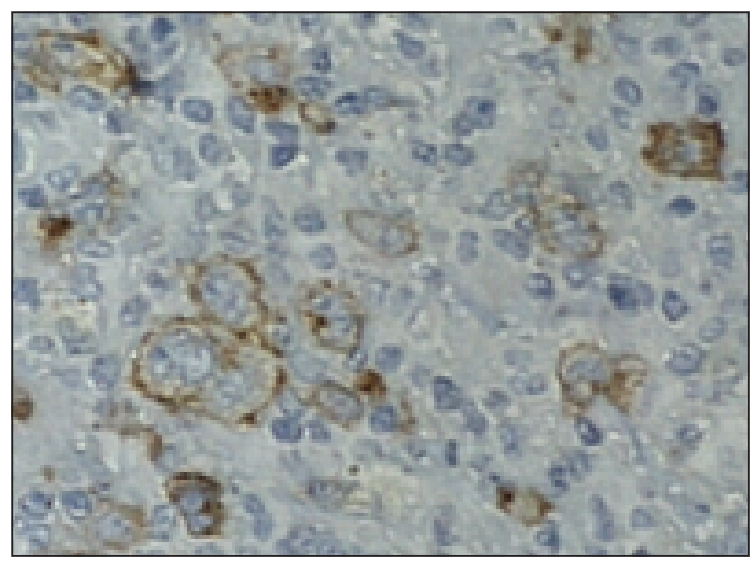

3) Areas rurales de países desarrollados: características histológicas y patrones de incidencia intermedios entre los presentados en países en desarrollo y áreas urbanas de países desarrollados.

4) Oriente: se observa una baja incidencia en todos los grupos de edad (26).

En la muestra analizada observamos un patrón epidemiológico intermedio, con características de país en desarrollo (alta incidencia en todos los grupos de edad) y de país desarrollado (predominio de esclerosis nodular, con alta incidencia en adultos jóvenes).

En Colombia, en 1971, se realizó un estudio de patrones epidemiológicos en 121 casos de linfoma 
Cuadro 2. Supervivencia libre de recurrencias (SLR) y supervivencia global (SG) a 60 meses según características clínicas y estado viral.

\begin{tabular}{|c|c|c|c|c|c|}
\hline & $\begin{array}{r}\text { Número de } \\
\text { pacientes }\end{array}$ & SLR (\%) & $p^{*}$ & SG (\%) & $\mathbf{P}^{*}$ \\
\hline \multicolumn{6}{|l|}{ Edad (años) } \\
\hline$<18$ & 18 & $16(88,89)$ & & $17(94,44)$ & \\
\hline$>18$ & 39 & $28(71,19)$ & 0,13 & $36(92,31)$ & 0,84 \\
\hline \multicolumn{6}{|l|}{ Estadio } \\
\hline I & 15 & $13(86,67)$ & & $14(93,33)$ & \\
\hline II & 15 & $12(80,00)$ & & $14(93,33)$ & \\
\hline III & 19 & $15(78,95)$ & & $18(94,74)$ & \\
\hline IV & 7 & $3(42,86)$ & 0,37 & $6(85,71)$ & 0,94 \\
\hline \multicolumn{6}{|c|}{ Tipo de tratamiento } \\
\hline ABVD & 32 & $22(68,75)$ & & $30(93,75)$ & \\
\hline OPPA/COPP & 17 & $15(88,24)$ & & $16(94,12)$ & \\
\hline RT/ChIVPP & 8 & $7(87,50)$ & 0,29 & $7(87,5)$ & 0,82 \\
\hline \multicolumn{6}{|l|}{ LMP-1 } \\
\hline Positivo & 32 & $24(93,55)$ & & $31(96,88)$ & \\
\hline Negativo & 25 & $14(56,00)$ & 0,0008 & $22(80,22)$ & 0,18 \\
\hline \multicolumn{6}{|l|}{ EBER } \\
\hline Positivo & 37 & $34(91,89)$ & & $36(97,3)$ & \\
\hline Negativo & 20 & $10(50,00)$ & 0,0002 & $17(85,00)$ & 0,079 \\
\hline
\end{tabular}

* $p$ log-rank test

Cuadro 3. Análisis multivariado del riesgo relativo de recurrencia según datos clínicos y estado viral.

\begin{tabular}{lccc}
\hline & RR de recurrencia & IC95\% & P \\
\hline Edad & 1,017 & $0,958-1,078$ & \\
Estadio & 1 & & \\
I & 1,234 & $0,186-8,178$ & 0,796 \\
II & 1,542 & $0,251-9,475$ & 0,672 \\
III & 1,793 & $0,263-12,23$ & 0,500 \\
IV & 1 & & \\
Tipo de tratamiento & 0,878 & $0,121-6,376$ & 0,897 \\
ABVD & 0,697 & $0,054-8,998$ & 0,782 \\
OPPA+COPP & 1 & & \\
Otro & 8,061 & $1,82-33,858$ & 0,006 \\
EBER & & & \\
Positivo & & & \\
Negativo & & & \\
\hline
\end{tabular}

Nota: modelo de regresión de Cox

RR: riesgo relativo; IC: intervalo de confianza

de Hodgkin en la Universidad del Valle, Cali. En este estudio se detectó un pico de incidencia en la niñez y un segundo pico después de los 50 años de edad, más del $50 \%$ de los casos correspondieron a los subtipos de celularidad mixta y depleción linfocitaria; estos últimos eran casos de peor pronóstico (27). En nuestro estudio, los subtipos histológicos de celularidad mixta y depleción linfocitaria no fueron los más prevalentes; la mayoría de casos diagnosticados correspondieron a esclerosis nodular, lo cual puede deberse a diferencias en las clasificaciones utilizadas. Actualmente, la clasificación se basa en hallazgos morfológicos, inmunofenotípicos y clínicos que no fueron tenidos en cuenta en el estudio realizado por Pelayo Correa (27). 
En otro estudio de linfoma de Hodgkin realizado en Colombia por Palacios en 1997 en la Clínica Fundación Santa Fe de Bogotá, se observó que el mayor porcentaje de casos de linfoma de Hodgkin analizados por histología e inmunohistoquímica presentaba el subtipo de esclerosis nodular (57,9\%) con picos en adultos jóvenes, en adultos viejos y uno pequeño en niños. Este patrón es similar al observado en nuestro estudio y al reportado en zonas rurales de países desarrollados (28).

\section{Presencia de virus de Epstein-Barr}

El alto porcentaje de detección de virus de Epstein-Barr en el total de la muestra estudiada y dentro de cada tipo histológico sugiere un papel importante de este virus en la patogénesis de este tumor en Colombia, con mayor prevalencia de la de países desarrollados y menor de la de otros países en vía de desarrollo como Perú y Honduras $(14,17)$.

La presencia de virus de Epstein-Barr fue significativamente mayor en el grupo de niños y adultos mayores de 50 años, lo cual puede ser debido a diferencias en estratificación económica, mezcla de diferentes poblaciones debida posiblemente a migración, exposición a agentes infecciosos y a factores propios del huésped relacionados con la edad (inmunocompetencia) (29). Como consecuencia, el virus en estos casos puede establecer un mayor número de ciclos líticos y se pueden generar altos títulos virales

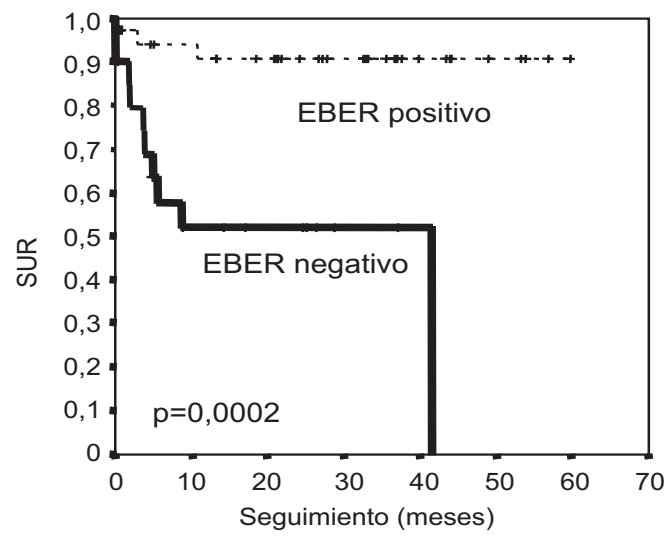

que aumentarían el riesgo de inmortalización de linfocitos en ganglios linfáticos y, así mismo, el riesgo de desarrollar linfoma de Hodgkin, lo que explicaría la presencia de infección en grupos de edad susceptibles como niños y adultos viejos (29).

Jarret y colaboradores (30) describen tres grupos de linfoma de Hodgkin de acuerdo con la edad en el momento del diagnóstico y con la presencia de infección con virus de Epstein-Barr: la primera se presenta en niños y se asocia con presencia de virus de Epstein-Barr, el tipo histológico predominante es el de celularidad mixta y tiene alta incidencia en países en vía de desarrollo. La segunda, también se asocia con virus de EpsteinBarr, el subtipo de celularidad mixta también es el prevalente, pero afecta predominantemente a adultos viejos y muestra menor variabilidad geográfica. La tercera no se asocia con virus de Epstein-Barr, afecta a adultos jóvenes y el tipo histológico prevalente es el de esclerosis nodular y se presenta en países desarrollados.

De acuerdo con esta clasificación, nuestros casos corresponden a una categoría intermedia, como país en vía de desarrollo, con alta prevalencia de virus de Epstein-Barr en todos los grupos de edad, con alto porcentaje de infección en los subtipos de celularidad mixta y esclerosis nodular.

Los pacientes positivos para virus de Epstein-Barr mostraron una mejor respuesta al tratamiento con menor tendencia a presentar recaídas en

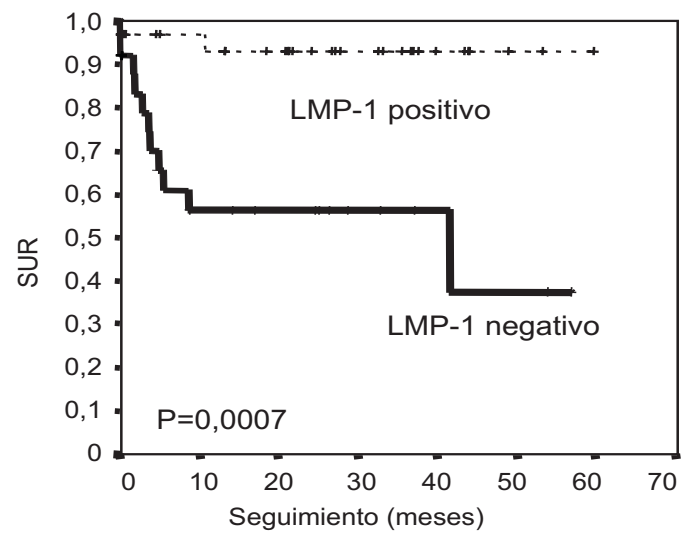

Figura 2. Curvas de supervivencia libre de recurrencia para casos positivos y negativos para virus de Epstein-Barr. 
comparación con los negativos para el virus. Esta asociación fue independiente del tipo de tratamiento que recibieron los pacientes. Estos resultados sugieren un valor pronóstico favorable de la presencia de virus de Epstein-Barr en las células tumorales de linfoma de Hodgkin. Tal como lo muestran otros estudios, la presencia de virus de Epstein-Barr favorece la respuesta al tratamiento $(19,20)$ y muestra una asociación significativa entre la expresión de LMP-1 en células de Reed-Stenberg y una mejor supervivencia en pacientes con linfoma de Hodgkin. Los casos analizados en nuestro estudio también muestran un alto porcentaje de expresión de LMP-1 (56,7\%) y, a su vez, estos pacientes presentan una mejor respuesta al tratamiento.

Estos hallazgos podrían sugerir que las células tumorales positivas para virus de Epstein-Barr son más sensibles a sufrir apoptosis inducida por la quimioterapia o que las células residuales después de la quimioterapia positivas para LMP-1 podrían ser blancos adecuados de la respuesta de linfocitos $T$ citotóxicos específicos de virus de Epstein-Barr y de células presentadoras de antígeno inmaduras (potente capacidad fagocítica) como células dendríticas y macrófagos, lo cual conduciría, a su vez, a la estimulación de linfocitos T para activación, diferenciación, proliferación y vigilancia inmunológica $(31,32)$ contra células remanentes infectadas con virus de Epstein-Barr disminuyendo la probabilidad de que los pacientes presenten recaídas después del tratamiento.

La presencia de virus de Epstein-Barr en los tumores de pacientes con linfoma de Hodgkin puede tener importantes implicaciones en el desarrollo de estrategias alternativas de tratamiento, como la transferencia adoptiva de linfocitos T estimulados in vitro con antígenos de virus de Epstein-Barr. Entre el $85 \%$ y el $90 \%$ de pacientes con linfoma de Hodgkin tienen una buena supervivencia después de la quimioterapia o la radioterapia. Sin embargo, $10 \%$ a $15 \%$ de los pacientes recaen después de la terapia inicial $y$, de éstos, sólo $50 \%$ entra en remisión secundaria. La terapia adoptiva con transferencia adoptiva de linfocitos $T$ ya ha sido aplicada en pacientes con enfermedades linfoproliferativas asociadas con virus de Epstein-Barr y ha resultado en la erradicación completa de los tumores (33). Este tipo de tratamiento puede ser importante en casos de enfermedad recurrente, en casos con múltiples recaídas, cuando existen efectos inmunosupresores inducidos por el tumor, por pobre presentación antigénica o pérdida de inmunogenicidad (33).

En conclusión, nuestros resultados muestran que los casos de linfoma de Hodgkin analizados pueden ser clasificados en un patrón epidemiológico intermedio, basados en los subtipos histológicos, en los grupos de edad y en la presencia de virus de Epstein-Barr en las células tumorales. Estos resultados sugieren que la demostración de virus de Epstein-Barr en todos los casos nuevos de linfoma de Hodgkin puede tener implicaciones importantes como posible factor pronóstico de respuesta al tratamiento. A su vez, esta detección podría tener gran importancia si en el futuro se utilizaran estrategias inmunoterapéuticas dirigidas contra antígenos virales en los casos positivos para virus de Epstein-Barr generando una respuesta favorable en este tipo de linfoma.

\section{Agradecimientos}

Los autores agradecen la colaboración del Grupo de Patología del Instituto Nacional de Cancerología y al Grupo de Inmunobiología de la Pontificia Universidad Javeriana.

\section{Referencias}

1. Instituto Nacional de Cancerología de Colombia. Registro institucional de cáncer. División de epidemiología y prevención. Grupo de registro y seguimiento. Bogotá: Instituto Nacional de Cancerología; 1998.

2. Pinto A, Aldinucci D, Gloghini A, Zaganel V, De Luliis A, Improta S, et al. The role of esosinophils in the pathobiology of Hodgkin's Disease. Ann Oncol 1997; 8(Suppl.2):S89-S96.

3. Herbst H, Steinbrecher E, Niedditek G, Young L, Brooks L, Mûller-Lantzsch N, et al. Distribution and phenotype of Epstein-Barr virus-harboring cells in Hodgkin's Disease. Blood 1992;80:484-91.

4. Grässer F, Murray P, Kremmer E, Klein K, Remberger W, Feiden G, et al. Monoclonal antibodies directed against the Epstein-Barr virus-encoded nuclear antigen 
1 (EBNA-1): immunohistologic detection of EBNA-1 in the malignant cells of Hodgkin's disease. Blood 1994; 11:3792-8.

5. Weiss L, Chen Y, Liu X, Shibata D. Epstein-Barr virus and Hodgkin's Disease. A correlative in situ hibridization and polymerase chain reaction study. Am J Pathol 1991; 139:1259-65.

6. Herbst H. Epstein-Barr virus in Hodgkin's Disease. Sem Cancer Biol 1996;7:183-9.

7. Herbst $\mathbf{H}$, Raff $\mathbf{T}$, Stein $\mathbf{H}$. Phenotypic modulation of Hodgkin and Reed-Sternberg cells by Epstein-Barr. J Pathol 1996;179:54-9.

8. Devergne O, Hatzivassiliou E, Izumi K, Kaye K, Kleijnen M, Kieff E, et al. Association of TRAF1, TRAF2 and TRAF3 with an Epstein-Barr virus LMP-1 domain important for B-lymphocyte transformation: role in NFkB activation. Mol and Cell Biol 1996;16:7098-108.

9. Jeffrey IC. Epstein-Barr Virus infection. $\mathrm{N}$ Engl J Med 2000;343:481-91.

10. Preciado M, De-Matteo E, Diez B, Menarguez J, Ginstein S. Presence of Epstein-Barr virus and strain type assignment in Argentine childhood Hodgkin's Disease. Blood 1995;86:3922-9.

11. Quintanilla L, Gamboa A, Gamez I, Angeles A, Mohar A. Association of Epstein-Barr virus latent membrane protein and Hodgkin's Disease in Mexico. Mol Pathol 1995;8:675-9.

12. Huh J, Park C, Juhng S, Kim C, Poppema S. A pathologic study of Hodgkin Disease in Korea and its association with Epstein-Barr virus infection. Cancer 1996;77:949-55.

13. Zhu Z, Hamilton S, Yan Q, Pallesen G. The association between Epstein-Barr virus and Chinese Hodgkin's Disease. Int J Cancer 1993;55:359-63.

14. Chang K, Albujar P, Chen Y, Johnson R, Weiss L. High prevalence of Epstein-Barr virus in the ReedSternberg cells of Hodgkin's disease occurring in Perú. Blood 1993;81:496-501.

15. Monterroso V, Zhou Y, Koo S, Glackin C, Bujan W, Medeiros J. Hodgkin's Disease in Costa Rica. A report of 40 cases analyzed for Epstein-Barr Virus. Am J Clin Pathol 1999;109:618-24.

16. Vasallo J, Metze K, Traina F, Souza C, Larand-Metze I. Expression of Epstein-Barr virus in classical Hodgkin's lymphomas in Brazilian adult patients. Haematologica 2001;86:1227-8.

17. Ambinder R, Brownin P, Lorenzana I, Leventhal B, Cosenza H, Mann R, et al. Epstein-Barr virus and childhood Hodgkin's disease in Honduras and the United States. Blood 1992;81:452-67.

18. Glaser S, Lin R, Stewart S, Ambinder R, Jarrett R, Brousset $\mathbf{P}$, et al. Epstein-Barr virus-associated
Hodgkin's Disese: epidemiologic characteristics in international data. Int J Cancer 1997;70:375-82.

19. Clarke C, Glaser S, Dorfman R, Mann R, DiGuisseppe J, Prehn A, et al. Epstein-Barr virus and survival after Hodgkin's disease in a populationbased series of women. Cancer 2001;91:1579-87.

20. Morente M, Piris M, Abraira V, Acevedo A, Aguilera B, Bellas C, et al. Adverse clinical outcome in Hodgkin's disease is associated with loss of retinoblastoma protein expression, high Ki67 proliferation index and absence of Epstein-Barr virus-latent membrane protein 1 expression. Blood 1997;90:2429.

21. Wasielewski R, Wiebusch A, Mengel, M. Clinical relevance of Epstein-Barr virus detection in Hodgkin's disease. Mod Pathol 2002;15:269A.

22. Harris N. Hodgkin's lymphomas: classification, diagnosis, and grading. Sem Hematol 1999; 36:220-32.

23. Murray P, Constandinov C, Crocker J, Young L, Ambinder R. Analysis of major histocompatibility complex class I, TAP expression and LMP2 epitope sequence in Epstein-Barr virus positive Hodgkin's disease. Blood 1998; 92:2477-83.

24. Mohammad A, Ronda A, Medeiros J, Weiss L. Immunophenotype of Reed-Sternberg cells and Hodgkin's disease cells in sequential biopsy specimens of Hodgkin Disease. A paraffin-section immunohistochemical study using the heat induced epitope retrieval method. Am J Clin Pathol 1997;108:54-9.

25. Khan G, Coates P, Kangro H. Epstein-Barr Virus (EBV) encoded small RNAs: targets for detection by in situ hybridisation with oligonucleotide probes. J Clin Pathol 1992;45:616-20.

26. Armstrong A, Alexander F, Cartwright R, Angus B, Krajewski A, Wright D, et al. Epstein-Barr virus and Hodgkin's disease: further evidence for three disease hypothesis. Leukemia 1998;12:1272-6.

27. Pelayo C, O' Conor G. Epidemiologic patterns of Hodgkin's disease. Int J Cancer 1971;8:192-201.

28. Palacios D, García C, Andrade R, García A. Enfermedad de Hodgkin: análisis de 309 casos diagnosticados en la Fundación Santa Fe de Bogotá. Acta Med Colomb 1997;22:268-76.

29. Kanegane H, Kanegane $\mathrm{CH}$, Yachie A, Miyawaki T, Tosato G. Infectious mononucleosis as a disease of early childhood in Japan caused by primary EpsteinBarr virus infection. Acta Pediatrica Japonica 1997; 39:166-71.

30. Jarret R, MacKenzie J. Epstein-Barr virus and other candidate viruses in the pathogenesis of Hodgkin's disease. Sem Hematol 1999;36:260-9.

31. Oudejans J, Jiwa N, Kummer J, Horstman A, Vos W, Baak P, et al. Analysis of major histocompatibility 
complex class I expression on Reed-Sternberg cells in relation to the cytotoxic T-cell response in Epstein-Barr virus-positive and -negative Hodgkin's disease. Blood 1996;87:3849-51.

32. Khanna R, Burrows S, Nicholls J. Identification of cytotoxic T cell epitopes within Epstein-Barr Virus (EBV) oncogene latent membrane protein 1 (LMP1): evidence for HLA -A2 supertype-restricted immune recognition of EBV cytotoxic T lymphocytes. Eur J Immunol 1998;28: 451-8.

33. Rooney C, Colton A, Heslop H. Control of virusinduced lymphoproliferation: Epstein-Barr virus-induced lymphoproliferation and host immunity. Mol Med Tod 1997;3:24-30 